\title{
Transaction
}

\section{Thermal Conductivity of Polyurethane Sheets Containing Alumina Nanofibers}

\author{
Koji Nakane $\#$, Shinya Ichikawa, Shuya Gao, Mikita Seto, \\ Satoshi Irie, Susumu Yonezawa, and Nobuo Ogata
}

\author{
Graduate School of Engineering, University of Fukui, 3-9-1 Bunkyo, Fukui 910-8507, Japan
}

\begin{abstract}
Alumina nanofibers were formed by heating poly(vinyl alcohol) (PVA)/boehmite composite nanofibers at various temperature. Polyurethane sheets containing the alumina nanofibers were formed by impregnation of alumina nanofiber mats with polyurethane. Thermal conductivity of the sheet containing the non-porous $\alpha$-alumina nanofibers of $5.7 \mathrm{vol} \%$ was $1.29 \mathrm{~W} / \mathrm{mK}$. The aligned nanofibers act as a linear heat-transfer pathway in the sheet and thus high thermal conductivity was achieved at a low alumina content. The sheets containing the aligned alumina nanofibers had anisotropic thermal conductivity in the plane direction of the sheet.
\end{abstract}

(Received 10 July, 2014 ; Accepted 29 October, 2014)

\section{Introduction}

With ongoing progress in the development of electric devices, much attention has been paid to heat dissipation performance of electrical insulation materials. Polymeric materials have good moldability but also thermal insulating properties. Thus, improvements in the thermal conductivity of polymeric materials have been needed to allow their use in electronics. Consequently, the compounding of thermally conductive inorganic particles, such as silica, alumina, aluminum nitride (AN), boron nitride $(\mathrm{BN})$, in polymer matrices has been investigated in order to improve thermal conductivity of polymeric materials [1-4].

There are recent reports on the thermal conductivity of polymers filled with BN particles [5-7]. Muratov et al. have investigated the thermal conductivity of polypropylene/BN particle composites [6]. They used two types of BN particles: high-purity hexagonal BN nanopowder (particle size $140 \mathrm{~nm}$ ) and hexagonal BN micron-sized powder $(5 \mu \mathrm{m})$. The large amount, the high quality and the small particle size of $\mathrm{BN}$ in the composites appears to improve their thermal conductive properties $(0.629 \mathrm{~W} / \mathrm{mK}$ at $4 \mathrm{wt} \%$ of $\mathrm{BN}$ nanopowder). Kim et al. modified the surfaces of BN particles $(12 \mu \mathrm{m})$ with surface curing agents and used them to form epoxy/ BN composites. They reported that the surface modification of BN increases the thermal conductivity of the composites $(4.11 \mathrm{~W} / \mathrm{mK}$ at $70 \mathrm{wt} \%$ of modified BN particle) [7]. Choi and Kim investigated the thermal

\# corresponding author conductivity of the epoxy composites with a binary particle of alumina and AN [8]. The thermal conductivity of a composite having large-sized AN $(10 \mu \mathrm{m})$ and smallsized alumina $(0.5 \mu \mathrm{m})$ particles was found to be $3.402 \mathrm{~W} / \mathrm{mK}$ at $58.4 \mathrm{vol} \%$ total filler content.

In general, particle contents above $50 \mathrm{vol} \%$ are needed to form a heat conduction pass in the composites. Our idea is to use inorganic nanofibers, several hundred nanometers in diameter, as filler in the composites instead of the inorganic particle fillers. By doing so, we considered that the heat conduction pass will be introduced into the composites very easily with a low filler content because the L/D of nanofibers is, in theory, infinity.

Alumina is the second-most prevalent element in the earth's crust, next to silica, and thus the price is cheaper than those of other inorganic materials such as $\mathrm{AN}$ and BN. In addition, alumina nanofibers can easily be prepared by using the electrospinning (ES) technique [911]. We have also formed alumina nanofibers by heating poly(vinyl alcohol) (PVA)/boehmite $\left[\mathrm{AlO}(\mathrm{OH}) \cdot \mathrm{H}_{2} \mathrm{O}\right]$ nanoparticle composite nanofibers obtained by ES [12]. Thus, in this study, we used alumina nanofibers as filler for polyurethane sheets and then investigated thermal conductivity of the sheets to develop a new thermally conductive composite with low filler content. We also investigated effects of the alignment of the alumina nanofibers in the sheets upon the thermal conductivity of the sheets. Alumina nanofiber mat can be easily impregnated with a raw mixture of thermosetting resin because the mixture has a low viscosity. Thus, polyurethane was used as a model resin in this research. 
The sheets formed would be applied as high-performance thermal conductive and flexible sheets for electronic parts such as power transistors and integrated circuit chips.

\section{Experimental}

\subsection{Preparation of Alumina Nanofibers through PVA/Boehmite Composite Precursor Nanofibers Using Electrospinning Technique}

Boehmite nanoparticles (Disperal P-2, dispersed particle size : $25 \mathrm{~nm}$ ) were kindly gifted from Sasol Japan KK. PVA (degree of polymerization : 1500, Wako Pure Chemicals Ind., Ltd., Japan) $10 \mathrm{wt} \%$ aqueous solution was prepared. Boehmite nanoparticles were dispersed into the PVA solution (spinning solution). The spinning solution was loaded into a plastic syringe $(2 \mathrm{ml})$ equipped with a needle. The solution extrusion rate was $0.015 \mathrm{ml} / \mathrm{min}$. The collector [copper plate or rotating drum collector (diameter: $160 \mathrm{~mm}$, rotating speed: $4000 \mathrm{rpm}$ )] was grounded, and the distance between the tip of the needle and the collector was $150 \mathrm{~mm}$. A voltage of 15.0-20.0 kV was applied to the needle, and then the PVA/boehmite (PVA/alumina $=70 / 30 \mathrm{wt} \%$ ) composite nanofibers were deposited on a collector as a nonwoven fabric. The PVA/boehmite composite nanofibers were used as a precursor of alumina nanofibers.

The precursor nanofibers obtained were heated in air up to a given temperature for $5 \mathrm{~h}$ in an electric furnace (in air), and they transformed into alumina nanofibers.

\subsection{Formation of Polyurethane Sheets Containing Alumina Nanofibers}

Polyurethane sheets (ca. $200 \mu \mathrm{m}$ in thickness) containing alumina nanofibers were prepared as below. A raw mixture of polyurethane resin was prepared by mixing polyisocyanate (1.92 g, CORONATE HXR, Nippon Polyurethane Industry Co., Ltd., Japan) and polyol (5.0 g, NIPPOLLAN 141, Nippon Polyurethane Industry Co., Ltd., Japan). Alumina nanofiber mats were impregnated with the mixture and were placed under vacuum and cured at $120^{\circ} \mathrm{C}$. The alumina content (vol\%) in the sheet was calculated by using the density of alumina, $3.965 \mathrm{~g} / \mathrm{cm}^{3}$ [8].

\subsection{Characterization}

The structure of the nanofibers was observed with a scanning electron microscope (SEM) (Keyence VE-9800, Japan) and a transmission electron microscope (TEM) (JEOL JEM-2100, Japan). From the SEM images, we estimated the fiber diameter and the standard deviations at each sample. Thermogravimetric (TG) analysis was performed in air to estimate the alumina content in the polyurethane sheet at a heating rate of $10{ }^{\circ} \mathrm{C} / \mathrm{min}$ (Shimadzu DTG-60, Japan). X-ray diffraction (XRD) patterns were taken using the $\mathrm{Ni}$-filtered $\mathrm{CuK} \alpha$ radiation (30 kV, 15 mA) (Rigaku Miniflex II, Japan). The specific surface area of the nanofibers were estimated from the nitrogen adsorption isotherms $\left(-196^{\circ} \mathrm{C}\right)$ measured with Micromeritics TriStar 3000, USA.

Thermal conductivity in the plane direction of the sheet was measured with Laser PIT (ULVAC, Inc., Japan) at room temperature. This system uses the scanning laser heating AC method (Angstrom method) to measure the in plane thermal diffusivity of the sheet [13]. The sample size was $3 \mathrm{~mm}$ wide $\times 25 \mathrm{~mm}$ long $\times$ ca. $200 \mu \mathrm{m}$ thick.

\section{Results and Discussion}

\subsection{Properties of Alumina Nanofibers Obtained from PVA/Boehmite Precursors}

Fig. 1 shows the SEM images of the PVA/boehmite precursor nanofibers. The precursor nanofibers were prepared from spinning solution at the mass ratio of alumina/PVA being 30/70 wt $\%$ which can produce wellformed precursor nanofibers. The average fiber diameter and the specific surface area of the precursors in Fig. 1 (a) were $341 \mathrm{~nm}$ and $6.4 \mathrm{~m}^{2} / \mathrm{g}$, respectively. Aligned nanofibers were easily obtained by using the rotating collector for ES [Fig. 1 (b)]. The average fiber diameter and specific surface area of the aligned precursors were $360 \mathrm{~nm}$ and $5.9 \mathrm{~m}^{2} / \mathrm{g}$, respectively. There are few differences in the average diameter and specific surface area between the unoriented and aligned precursors.

Fig. 2 shows TEM images of the PVA/boehmite precursor nanofibers. From these images, it is likely that boehmite needle-like nanoparticles are dispersed uniformly in the PVA matrix because the dark contrast can be observed throughout the fiber. The selected- area electron diffraction in Fig. 2 (b) indicates the rod-like boehmite nanoparticles are aligned along the fiber axis.

Fig. 3 shows an SEM image of the alumina nanofibers prepared by heating the precursors [Fig. 1 (b)]
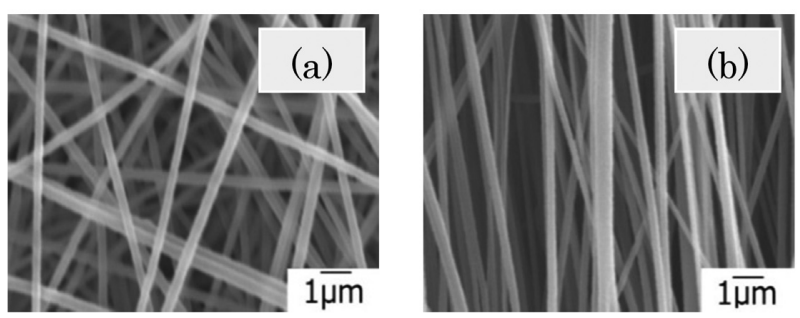

Fig. 1 SEM images of PVA/boehmite (PVA/alumina = $70 / 30 \mathrm{wt} \%$ ) precursor nanofibers [(a) unoriented, (b) aligned]. 

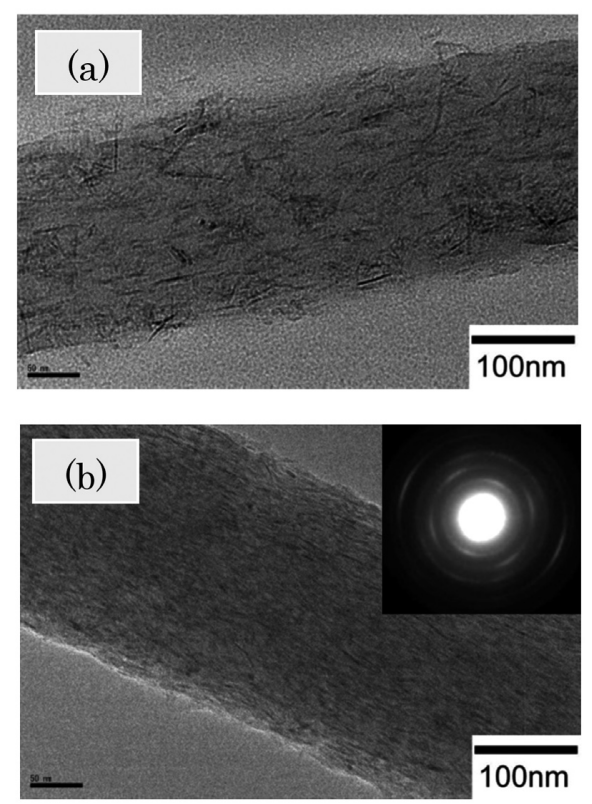

Fig. 2 TEM images of PVA/boehmite precursor nanofibers [PVA/alumina $=$ (a) 90/10 wt\%, (b) $70 / 30 \mathrm{wt} \%$ ]. The inset of part (b) is selectedarea electron diffraction of the precursor.

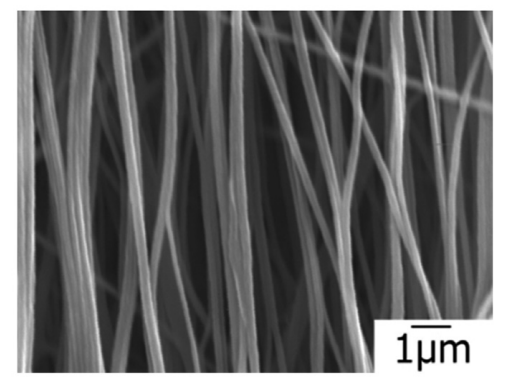

Fig. 3 SEM image of the aligned alumina nanofibers prepared by heating of the precursor nanofibers at $500{ }^{\circ} \mathrm{C}$ for $5 \mathrm{~h}$ in air.

at $500^{\circ} \mathrm{C}$ for $5 \mathrm{~h}$ in air. The aligned structure of the fibers remains after the heat treatment. We have confirmed that the weight residues above $500^{\circ} \mathrm{C}$ (the alumina contents in the precursor nanofibers) reflect the boehmite contents in the spinning solution by thermogravimetric analysis [12].

Fig. 4 shows the relationship between the average diameter and the specific surface area of the alumina nanofibers. The average diameter of the alumina nanofiber heated at $500^{\circ} \mathrm{C}$ is almost the same as that of the precursor nanofibers. The diameter of the alumina nanofibers would be influenced by following two factors : (1) thermal decomposition of PVA matrix in the precursors, (2) shrinkage of the nanofibers along the fiber axis by the heating. On the other hand, the specific surface area of the alumina nanofibers heated at $500^{\circ} \mathrm{C}$ greatly increased $\left(291.3 \mathrm{~m}^{2} / \mathrm{g}\right)$. Then the diameter and the specific surface area gradually decreased with the increase in heating temperature due to the sintering and the phase transition of alumina. At $1200^{\circ} \mathrm{C}$ the diameter

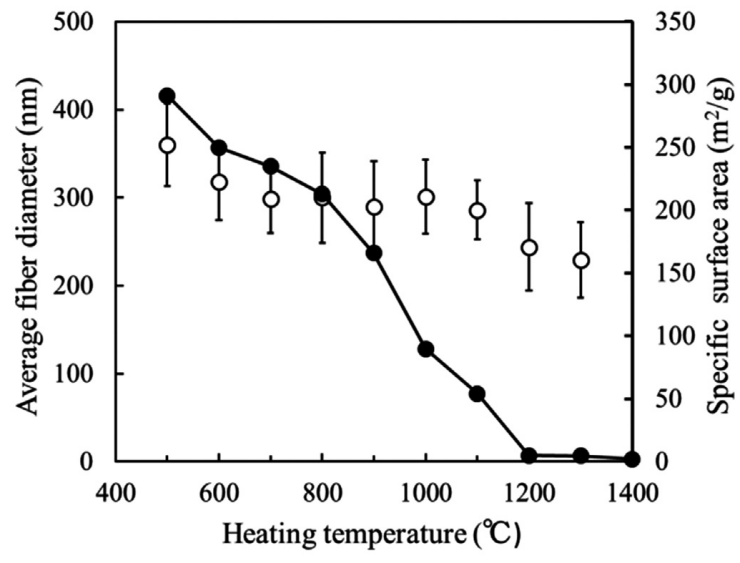

Fig. 4 Effect of heating temperature on average diameter $(O)$ and specific surface area $(\bullet)$ of alumina nanofibers obtained.

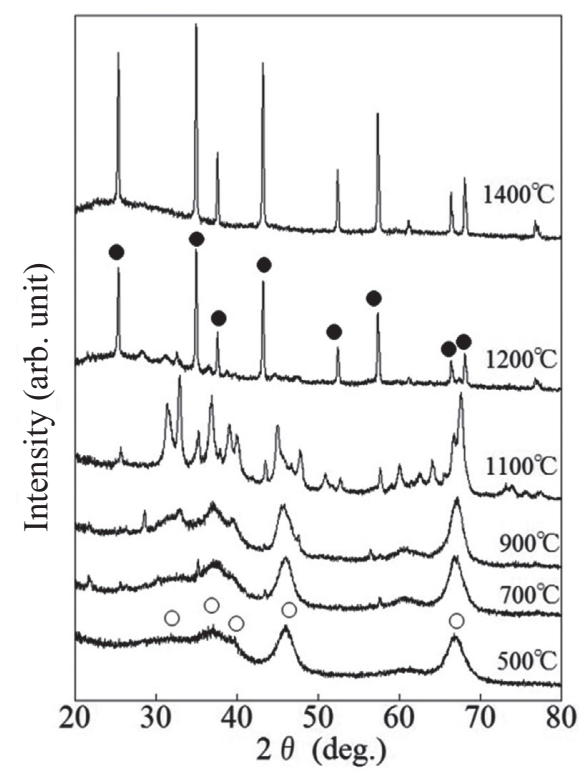

Fig. 5 XRD curves of alumina nanofibers obtained ( $O$ : $\gamma$-alumina, $\bullet: \alpha$-alumina).

became $244 \mathrm{~nm}$ and the specific surface area was reduced to $5.4 \mathrm{~m}^{2} / \mathrm{g}$, which was equivalent to that of the precursor nanofiber $\left(6.4 \mathrm{~m}^{2} / \mathrm{g}\right)$. The shape of the precursor nanofibers remained after heating of the precursors at $1300^{\circ} \mathrm{C}$ although it became brittle due to the high crystallinity.

Fig. 5 shows the XRD curves of the alumina nanofibers. $\gamma$-Alumina (spinel type crystal) was formed by heating from 500 to $900^{\circ} \mathrm{C}$, and $\delta$ - or $\theta$-alumina was formed at around $1100^{\circ} \mathrm{C}$. Furthermore, $\alpha$-alumina was formed at $1200^{\circ} \mathrm{C}$, and the peak intensity became sharp at $1400^{\circ} \mathrm{C}$. Thus it was found that non-porous $\alpha$-alumina nanofibers can be obtained by heating PVA/boehmite precursor nanofibers above $1200^{\circ} \mathrm{C}$.

\subsection{Thermal Conductivity of Polyurethane Sheets Containing Alumina Nanofibers}

Fig. 6 shows pictures of (a) the prepared $\alpha$-alumina 
nanofiber mat and (b) the polyurethane sheet containing the $\alpha$-alumina nanofiber mat. The sheet becomes semitransparent by impregnation of polyurethane into the alumina nanofiber mat.

Fig. 7 shows the SEM images of the polyurethane sheet containing the aligned alumina nanofibers. According to the cross-sectional view [Fig. 7 (a) (b)], polyurethane has successfully filled the space between the nanofibers, and the nanofibers (circular dots in this image represent the cross-section of the nanofibers) are distributed homogeneously in the polyurethane matrix. The nanofibers can be also observed in the surface of the sheet [Fig. 7 (c)], and it is likely that disconnection of the fibers does not occur as a result of the impregnation with polyurethane. On the other hand, there are few heattransfer pathways for alumina in the thickness direction of the sheet. Based on Fig. 7, we considered that the formed
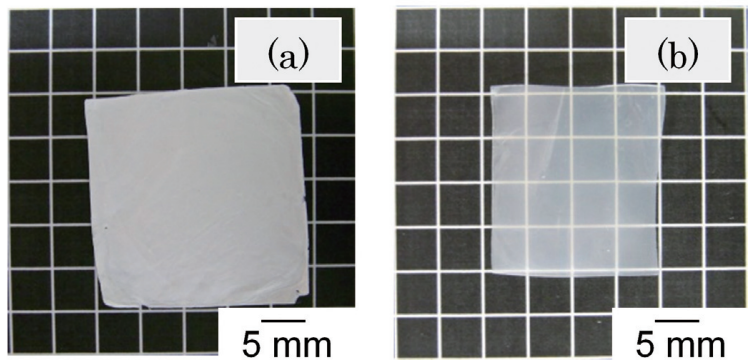

Fig. 6 Pictures of (a) the prepared $\alpha$-alumina nanofiber mat and (b) a polyurethane sheet containing the $\alpha$-alumina nanofiber mat.

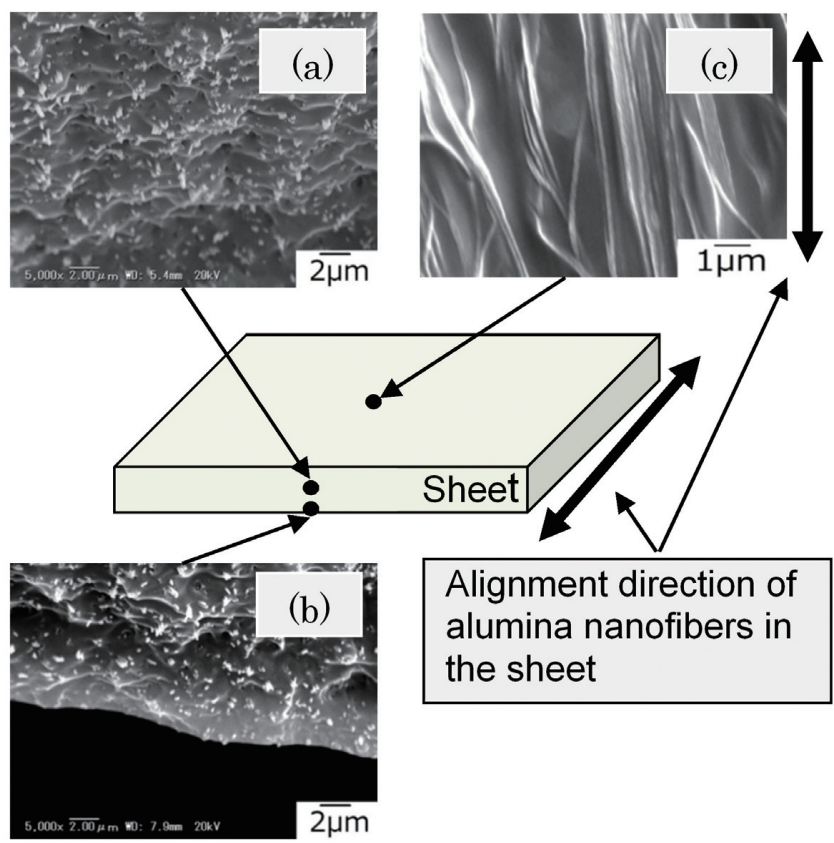

Fig. 7 SEM images of polyurethane sheet containing aligned alumina nanofibers [(a) the center of the cross-section, (b) the edge of the cross-section, (c) the surface of the sheet]. sheets would have better thermal conductivity in the plane direction of the sheets than in the thickness direction.

Fig. 8 shows the effects of the alumina content on the thermal conductivity of the sheets. Alumina nanofibers heated at $500,700,900$ or $1200^{\circ} \mathrm{C}$ were used to form the sheets. Black and white plots represent the nanofibers with and without aligned structures, respectively. The thermal conductivity of the as-prepared alumina nanofiber mat could not be measured because it was too brittle. The thermal conductivities of the sheets containing alumina nanofibers heated below $900^{\circ} \mathrm{C}$ are approximately the same as that of the pure polyurethane sheet. However, the values for the sheets increased remarkably when the $\alpha$-alumina nanofibers heated at $1200^{\circ} \mathrm{C}$ were used. This difference is due to the nonporous structure and the high crystallinity of $\alpha$-alumina nanofibers. Furthermore, the sheets containing the aligned $\alpha$-alumina nanofibers were found to have higher thermal conductivity than the sheets containing the $\alpha$-alumina nanofibers without aligned structures (the thermal conductivities of the sheets containing the aligned $\alpha$ alumina nanofibers were measured along the alignment direction of the nanofibers in the sheets). It is noteworthy that the thermal conductivity becomes more than $1 \mathrm{~W} / \mathrm{mK}$ with a mere $3 \mathrm{vol} \%$ alumina content. The value increases with increasing alumina content, reaching $1.29 \mathrm{~W} / \mathrm{mK}$ at $5.7 \mathrm{vol} \%$ of alumina. In contrast to reports using inorganic particles as filler $[2,4,6]$, it was found that the thermal conductivity of the polymeric materials can be effectively improved by using inorganic nanofibers as a

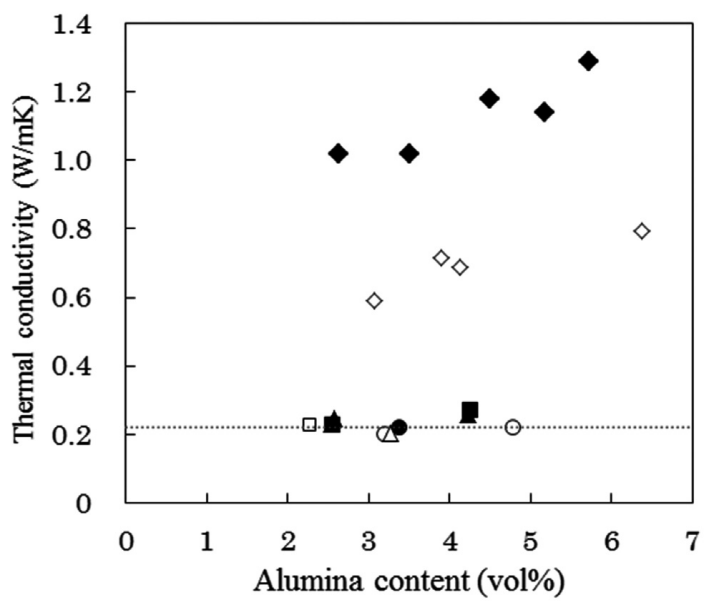

Fig. 8 Effect of alumina content of polyurethane/ alumina nanofiber sheets on the thermal conductivity. Black and white plots represent the alumina nanofibers with and without aligned structures, respectively (Heating temperature, $\bigcirc$ - : $500^{\circ} \mathrm{C}, \triangle \boldsymbol{\Delta}$ : $700^{\circ} \mathrm{C}, \square \mathbf{\square}: 900^{\circ} \mathrm{C}, \diamond \diamond$ : $\left.1200^{\circ} \mathrm{C}\right)$. The dotted line indicates the thermal conductivity of pure polyurethane, $0.22 \mathrm{~W} / \mathrm{mK}$. 


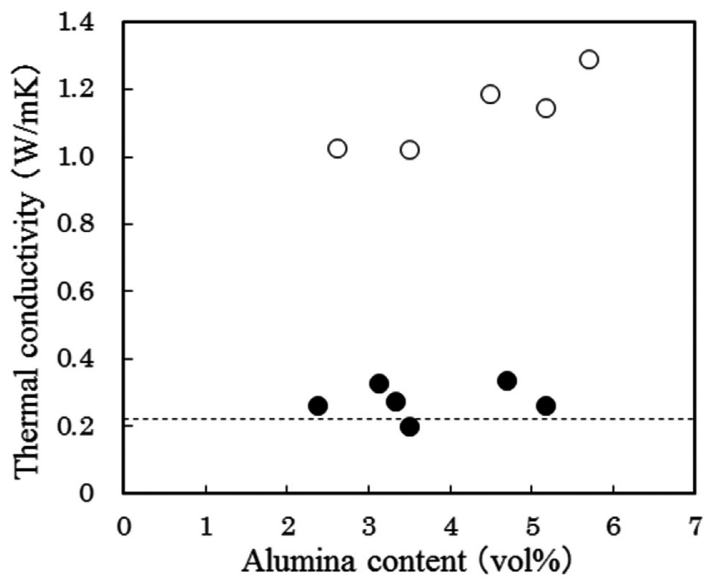

Fig. 9 Thermal conductivity of the sheet containing aligned $\alpha$-alumina nanofibers (Heating temperature, $\left.1200^{\circ} \mathrm{C}\right)$ in 2 directions, $(O)$ parallel and $(\bullet)$ perpendicular based on the alignment direction of the nanofibers in the sheet. The dotted line indicates the thermal conductivity of pure polyurethane, $0.22 \mathrm{~W} / \mathrm{mK}$.

filler. This improvement is due to the linear heat-transfer pathway of the aligned alumina nanofibers in the sheet.

We measured the thermal conductivity of the sheet containing aligned $\alpha$-alumina nanofibers in 2 directions, parallel and perpendicular based on the alignment direction of the nanofibers in the sheet. Fig. 9 shows the difference in the thermal conductivities of the sheet containing aligned $\alpha$-alumina nanofibers. The thermal conductivities parallel to the alumina nanofibers are obviously higher than those perpendiculars to the aligned fibers. This result indicates that the sheets containing aligned alumina nanofibers have anisotropic thermal conductivity in the plane direction of the sheet.

\section{Conclusion}

The PVA/boehmite composite precursor nanofibers were formed by ES using a PVA aqueous solution with dispersed boehmite nanoparticles as the spinning solution. The alumina nanofibers were obtained by heat-treatment of the precursors between 500 and $1400^{\circ} \mathrm{C}$. The alumina nanofiber mats were impregnated with polyurethane. The polyurethane sheet containing the aligned $\alpha$-alumina nanofibers showed good thermal conductivity parallel to the alumina nanofibers in the sheet. This thermally conductive sheet having the in-plate anisotropy will be available for creating high-performance electric devices.

\section{References}

1. Y. Agari, A. Ueda, M. Tanaka and S. Nagai, J. Appl. Polym. Sci., 40, 929 (1990).

2. S. Yu, P. Hing and X. Hu, Composite Part A, 33, 289 (2002).

3. Y. Agari, A. Ueda, and S. Nagai, J. Appl. Polym. Sci. , 49, 1625 (1993).

4. W. Zhou, S. Qi, Q. An, H. Zhao and N. Liu, Mater. Res. Bull., 42, 1863 (2007).

5. M. Harada, N. Hamaura, M. Ochi and Y. Agari, Composite Part B , 55, 306 (2013).

6. D. S. Muratov, D. V. Kuznetsov, I. A. II'inykh, I. N. Mazov, A. A. Stepashkin, V. V. Tcherdyntsev, J. Alloy Compd, 586, 5451 (2014).

7. K. Kim, M. Kim, Y. Hwang and J. Kim, Ceram. Int., 40, 2047 (2014).

8. S. Choi and J. Kim, Composite Part B, 51, 140 (2013).

9. G. Larsen, R. Velarde-Ortiz, K. Minchow, A. Barrero and L. G. Loscertales, J. Mater. Sci., 125, 1154 (2003).

10. R. W. Tuttle, A. Chowdury, E. T. Bender, R. D. Ramsier, J. L. Rapp and M. P. Espe, Appl. Surf. Sci., 254, 4925 (2008).

11. P. K. Panda and S. Ramakrishna, J. Mater. Sci., 42, 2189 (2007).

12. K. Nakane, M. Seto, S. Irie, T. Ogihara and N. Ogata, J. Appl. Polym. Sci., 121, 1774 (2011).

13. I. Hatta, Int. J. Thermophys., 11, 293 (1990). 